\title{
Manejo del neonato sospechoso e infectado de COVID-19 en la UCIN
}

\section{Management of the suspicious and infected neonate in the NICU}

Héctor Alberto Macías-Avilés

\begin{abstract}
Resumen
El SARS-CoV-2 es un coronavirus $\beta$ y se reportó por primera vez en diciembre de 2019 en Wuhan, China y el primer caso reportado de COVID-19 neonatal fue en febrero de 2020. Desde entonces han surgido preocupaciones acerca de la posible transmisión vertical de SARS-CoV-2 y su gravedad, pero la información sobre recién nacidos con COVID-19 confirmado o sospechado está aún limitada. Está reportado que es más común como una enfermedad asintomática o leve en comparación con los adultos. El recién nacido puede infectarse después del nacimiento, ya sea de su madre, familiar o dentro del entorno del hospital a través de gotitas de la vía respiratoria, fómites infectados y por el aire durante los procedimientos de aerosolización EI diagnóstico requiere la detección de la secuencia homóloga del virus del por RT-PCR de SAR-CoV-2 de la vía respiratoria superior (hisopado nasofaríngeo u orofaríngeo), vías respiratorias inferiores (esputo, aspirado endotraqueal o lavado broncoalveolar) o en sangre (suero). Por lo tanto, la atención médica en la unidad de cuidados intensivos neonatales de estos pacientes consiste en: prevenir, controlar y establecer medidas para asegurar el tratamiento adecuado de quienes potencialmente pueden infectarse. Los cuidados médicos y respiratorios aún no son claros y existen varias propuestas en estudios efectuados en distintos países. Estas recomendaciones de atención de recién nacidos de madres con COVID-19, confirmado o sospechoso, son específicas y pueden modificarse según las limitaciones de la infraestructura y disponibilidad de equipos de protección de cada centro hospitalario.
\end{abstract}

PALABRAS CLAVE. SARS CoV-2; COVID-19; recién nacidos; enfermedad asintomática; vía respiratoria; lavado broncoalveolar; suero sanguíneo

Abstract

SARS-COV-2 is a $\beta$-coronavirus and was first reported in December 2019 in Wuhan, China and the first reported case of neonatal COVID-19 was in february 2020, concerns have been raised about possible transmission of SARS-CoV-2 and its severity, but information on newborns with confirmed or suspected COVID-19 is still limited; its presentation has been reported to be more common as a mild or asymptomatic disease compared to adults. The newborn can become infected after birth, either from his mother, family member or within the hospital environment through droplets from the respiratory tract, infected fomites and through the air during aerosolization procedures. Diagnosis requires detection of the sequence RT-PCR virus homologue of SAR-CoV-2 from the upper respiratory tract (nasopharyngeal or oropharyngeal swab), lower respiratory tract (sputum, endotracheal aspirate or bronchoalveolar lavage) or blood (serum). The neonatal intensive care unit (NICU) objectives for these patients is preventing, controling and establishing measures to ensure the adequate management of these patients who can potentially become infected. Medical and respiratory management is not yet clear and there are several proposals in studies worldwide. But these recommendations for the care of newborns of mothers with confirmed or suspected COVID-19 are specific and can be modified by the limitations of the infrastructure and the availability of protective equipment in each hospital center.

KEYWORDS: SARS CoV-2; Neonatal COVID 19; Newborns; Asymptomatic Disease; Respiratory Tract; Bronchoalveolar Lavage; Blood Serum.
Jefe del Departamento de Neonatología

Instituto Nacional de Pediatría, Ciudad de México.

Recibido: 12 de mayo 2020

Aceptado: 16 de junio 2020

Correspondencia

Héctor Alberto Macías Avilés hectormaciasaviles@yahoo.com.mx

Este artículo debe citarse como Macías-Avilés HA. Manejo del neonato sospechoso e infectado de COVID-19 en la UCIN. Acta Pediatr Méx 2020; 41 (Supl 1):S101-S108. 


\section{INTRODUCCIÓN}

Desde diciembre de 2019, la infección por SARS-CoV-2 ha demostrado tener propagación rápida y la capacidad de infectar a la población en general susceptible. El patógeno pertenece al coronavirus de tipo $\beta$ (nuevo coronavirus 2019, COVID-19). La vía principal de transmisión es a través de gotitas respiratorias y por contacto, sin olvidar que estudios actuales han sugerido que el COVID 19 también se puede transmitir a través de la ruta fecal-oral. En cuanto a los neonatos, se han informado en China de 6 casos de recién nacidos con pruebas positivas de SARS-CoV-2 y no se puede descartar la ruta de transmisión vertical. ${ }^{1,2,3}$

La infección por COVID-19 puede causar daño potencial a los recién nacidos debido a que tienen inmunidad inmadura, por esa razón, diversos grupos de expertos en prevención y control de la infección en el período perinatal han presentado varias recomendaciones para la prevención y control de la infección neonatal.

\section{Definición}

Recién nacido sospechoso es el neonato hijo de madre con antecedentes de infección por SAR-CoV-2, entre 14 días antes del parto y 28 días después del parto, o el recién nacido directamente expuesto a personas infectadas confirmadas por SAR-CoV-2 (incluyendo miembros de la familia, cuidadores, personal médico y visitantes). Los bebés sospechosos están bajo esta consideración independientemente de si son sintomáticos o no. ${ }^{3}$

Recién nacido con infección confirmada por SAR-CoV-2, si se cumple 1 de los siguientes criterios: ${ }^{3}$ a. Muestra de hisopado del tracto respiratorio o de sangre analizadas por reacción en cadena de polimerasa en tiempo real (RT-PCR) positivas para RNA del SARSCoV-2. ${ }^{3}$

b. Secuenciación del gen del virus de muestra del tracto respiratorio o de la sangre altamente homóloga a SAR-CoV-2 Se recomienda si es posible tomar 2 muestras de sitios diferentes. ${ }^{3}$

c. Muestra de hisopado rectal, muestra la eficacia del tratamiento y determina el tiempo final de la cuarentena. ${ }^{3}$

Después de la reanimación y estabilización inicial, el recién nacido debe ser separado de su madre; si bien es difícil, la separación temporal de la madre y el recién nacido minimizará el riesgo de infección postnatal infantil por secreciones respiratorias maternas. Los beneficios de la separación pueden ser mayores en madres con enfermedad más grave y los posibles beneficios de la separación temporal materna y neonatal al nacer para disminuir el riesgo de infección del recién nacido se debe discutir con la madre antes del nacimiento. Todos los casos sospechosos o confirmados de infección neonatal por COVID-19 deben ser admitidos en la UCIN. ${ }^{4}$ El objetivo de esta revisión es el paciente que ingresa a la unidad de cuidados intensivos neonatales.

\section{Características de la unidad COVID-19}

La unidad debe contar con tres áreas separadas:

- Sala general: neonatos con otras patologías

- Sala de transición: casos sospechosos de COVID-19 
- Sala de aislamiento o cuarentena: casos confirmados de COVID-19.

En las dos últimas áreas el personal debe contar con aislamiento efectivo y equipo de protección personal óptimo, además tanto neonatos sospechosos y confirmados deben colocarse en incubadoras cerradas. Cada área debe contar con cubículos aislados con presión negativa o sistema de filtración de aire, paredes, pisos y techos de material liso, resistente y lavable que permita el uso de desinfectantes, con un filtro de acceso que cuente con lavabo con dispensadores de jabón germicida líquido, gel (alcohol isopropílico) y toallas desechables o sistema de aire para secado de manos.

Cada cubículo debe contar con el espacio suficiente para la ubicación de incubadora, el equipo de monitoreo frecuencia cardiaca, frecuencia respiratoria, temperatura, tensión arterial, saturación de oxígeno y soporte respiratorio, así como el espacio libre para el desplazamiento del personal que favorezca la seguridad del paciente. En cada cubículo o módulo deberán existir tomas fijas para el suministro de oxígeno medicinal, toma fija de aire comprimido, así como tomas fijas de aspiración controlada. Si no es posible contar con áreas aisladas para cada paciente, el espacio entre incubadoras debe ser de un mínimo de 2 metros. El personal médico y de enfermería debe ser el mínimo necesario y estar destinado exclusivamente a esta área de atención. ${ }^{3-6}$

\section{Cuadro clínico ${ }^{6}$}

Los hallazgos clínicos son inespecíficos, principalmente en el neonato prematuro, por lo que se debe monitorizar de forma continua los signos vitales. Se han descrito signos tempranos y tardíos.

\section{Primera semana}

Temperatura: hipotermia, hipertermia, normotermia.

Respiratorio: signos de dificultad respiratoria que puede ir desde la forma leve hasta la más grave.

Cardiovascular: taquicardia, bradicardia, hipotensión arterial, datos de choque.

Alimentación y gastrointestinal: hiporexia, vómito, distensión abdominal, diarrea.

Otros: letargia, hipoactividad.

\section{1 a 3 semanas}

Rash, síntomas gastrointestinales, sepsis neonatal tardía, choque séptico y miocarditis.

\section{Estudios de laboratorio}

El estudio especifico es RT-PCR para SAR-CoV-2, el primer hisopado se debe realizar entre las 24 y 36 horas y repetir 24 horas después. Se recomienda tomar la muestra simultáneamente de 2 sitios como nasofaringe y orofaringe; en pacientes intubados debe ser por aspirado endotraqueal o lavado bronquial y se puede tomar en ambos casos adicionalmente hisopado rectal. En neonatos con pruebas positivas deben realizarse pruebas adicionales cada 48 horas hasta obtener dos pruebas negativas consecutivas. ${ }^{6}$

Por otra parte existen estudios de laboratorio que ayudar a evaluar la evolución del paciente: biometría hemática completa, en la fase temprana puede ser normal y posteriormente presentar leucopenia con linfopenia y trombocitopenia; química sanguínea hay elevación de la fosfatasa 
alcalina, alanina aminotransferasa (ALT) aspartato aminotransferasa (AST), lactato deshidrogenasa (LDH), PCR, incremento de biomarcadores cardiacos (CPK, troponina, péptido natriurético tipo B), incremento de dímero D y ferritina. ${ }^{6,7,8}$

\section{Estudios de imagen}

Radiografía de tórax o ultrasonido pulmonar es probable que muestren datos sugestivos de neumonía y la radiografía de abdomen puede mostrar datos de íleo. ${ }^{6,7,8}$

\section{Panel viral}

El panel para virus respiratorios del tracto respiratorio alto y bajo está indicado cuando el neonato ingresa de su casa con sintomatología respiratoria y es sospechoso de infección por COVID-19, esto con la finalidad de evaluar la presencia de otros agentes virales; el SARS-CoV-2 se puede mezclar con otros agentes patógenos como influenza $A$, influenza $B$, virus sincicial respiratorio y virus de Epstein Barr. ${ }^{8}$

\section{Tratamiento}

Los recién nacidos deben permanecer en la unidad de cuidados intensivos neonatales, con aislamiento y medidas de prevención terciaria. En la actualidad, el principio del tratamiento es la atención de soporte, la monitorización y el tratamiento de las complicaciones. El aporte de líquidos y electrólitos intravenosos debe ser cauteloso para evitar o agravar el edema pulmonar; debe administrarse oxígeno suplementario para evitar la hipoxia. Puede iniciarse la vía enteral lo más pronto posible, la controversia en relación con la lactancia materna es que no hay duda de que la leche humana proporciona paso de anticuerpos al neonato contra SARS-CoV-2. Una madre COVID positiva representa mayor riesgo de contagio al recién nacido, por el contacto de gotas respiratorias generadas por ella. Por esto, de continuar la lactancia debe insistirse en las medidas de protección (lavado de manos, uso de mascarilla N95, etc.). Está descrita la coexistencia del virus en la leche; en el caso de madres con enfermedad grave puede recurrirse a la extracción o a leche de donadora. El neonato con síndrome de dificultad respiratoria grave debe colocarse en posición prona tres o cuatros veces al día, dosis altas de surfactante pulmonar exógeno, CPAP, alto flujo, ventilación convencional, ventilación oscilatoria de alta frecuencia (VAFO) óxido nítrico inhalado. Hasta el momento no existe un fármaco comprobado en contra del COVID-19, se debe evitar el uso inapropiado de antibióticos, especialmente antibióticos de amplio espectro y si existe evidencia de infección bacteriana secundaria, se deben usar antibióticos cautelosamente y no hay evidencia que respalde la efectividad de la gammaglobulina, el interferón o terapia hormonal.

Para todos los procedimientos que pueden producir aerosoles (intubación endotraqueal, ventilación no invasiva, reanimación cardiopulmonar, ventilación con bolsa autoinflable y mascarilla, broncoscopía, etc.) se requiere que el personal cuente con el equipo de protección personal completo como medida de aislamiento aéreo y seguir las siguientes medidas de protección y disminución de la aerosolización. 9,10,11

- Mantener al recién nacido dentro de la incubadora durante toda su estancia hospitalaria.

- Paciente con ventilación no invasiva, solo aspirar las secreciones respiratorias en caso de extrema necesidad. 
- Paciente en ventilación mecánica, utilizar circuito cerrado de aspiración.

- No desconectar el circuito del ventilador $y$, en caso de ser estrictamente necesario, hacerlo entre dos operadores, usar equipo de protección personal para procedimientos con aerosolización, seleccionar en el ventilador modo de "espera" o "CPAP". Con esto disminuye la cantidad de flujo de aire circulante y, por lo tanto, la liberación de aerosoles al ambiente.

- Se recomienda tener tapones en una bolsa con cierre y colocarlos en el circuito del ventilador y usarlos en estas circunstancias hasta reconectar al paciente.

- Para la extubación utilizar equipo de protección personal y realizar la maniobra entre dos operadores, colocar sobre la cara del paciente una cubierta de plástico transparente o caja de acrílico, aspirar la cavidad oral con sonda K29, y por cánula con sistema de aspiración cerrado, retirar la fijación y sostener el tubo con la mano, colocar el ventilador "en pausa" o CPAP, introducir una sonda de sistema de aspiración cerrado y retirar la cánula aspirando.

- Los circuitos e interfases utilizados en los pacientes con SARS-CoV-2 deben desecharse de acuerdo con la política institucional y regulaciones establecidas para el manejo de residuos peligrosos biológico-infecciosos.

- La bolsa autoinflable de reanimación debe tener reservorio cerrado y filtro HEPA (High Efficiency Particle Air), su uso está indicado tanto en los sistemas de ventilación invasiva como no-invasiva.
- Los filtros HEPA deben colocarse en la rama espiratoria e inspiratoria del circuito del ventilador, equipo de ventilación no invasiva (CPAP, VNI), entre la máscara, cánula endotraqueal, salida de la bolsa autoinflable o reanimador con pieza en $\mathrm{T}$.

Enseguida se exponen diferentes escenarios y recomendaciones de atención cuando las condiciones del centro hospitalario permiten el alojamiento:

\section{Neonato sospechoso y asintomático ${ }^{12,13,14}$}

Debe ingresar a una habitación individual, en incubadora, con medidas de aislamiento de contacto y por gotas con monitoreo de signos vitales (frecuencia cardiaca y respiratoria, temperatura, presión arterial y saturación oxígeno) y vigilancia clínica. Iniciar la alimentación y si las condiciones de la madre lo permiten, leche humana con todas las medidas de protección. Tomar RT-PCR para SAR-CoV-2 y, según la evolución, valorar la realización de biometría hemática y PCR. Si la prueba para SARS-CoV-2 resulta negativa y se descarta la infección puede suspenderse el aislamiento y volver a los cuidados rutinarios por parte de cuidador principal sano o personal de salud; mientras tanto deben evitarse las visitas.

\section{Neonato sospechoso y sintomático ${ }^{12-14}$}

Ingresarlo a una habitación individual, en incubadora, con medidas de aislamiento de contacto y por gotas, con monitoreo de signos vitales (frecuencia cardiaca y respiratoria, temperatura, presión arterial y saturación oxígeno) y vigilancia clínica. Si las condiciones lo permiten debe iniciarse la alimentación. Deben tomarse: RT-PCR para SARS CoV-2, biometría hemática, $\mathrm{PCR}$, radiografía de tórax y abdomen. El tratamiento no difiere del de cualquier neonato con 
los mismos síntomas, aplicando las medidas de soporte que requiera. En los casos de hijos de madre con infección confirmada, o con alta sospecha clínica-epidemiológica, para considerar un caso descartado en el neonato y poder retirar las medidas de aislamiento, se recomienda tener dos controles negativos de RT-PCR a las 24-48 horas. Se limitarán las visitas. Si se descarta la infección por SARS-CoV-2, el alta domiciliaria dependerá de la evolución clínica y disminución de los síntomas.

\section{Neonato confirmado y asintomático ${ }^{12-14}$}

Ingreso a una habitación separada del contacto infeccioso, en incubadora con medidas de aislamiento de contacto y por gotas, con monitoreo de signos vitales (frecuencia cardiaca, frecuencia respiratoria, temperatura, presión arterial y saturación oxígeno) y vigilancia clínica. Puede iniciar la vía oral, pero se debe aconsejar evitar la lactancia materna. Tomar RT-PCR para SARSCoV-2, biometría hemática, PCR. Se deben limitar las visitas.

\section{Neonato confirmado y sintomático ${ }^{12-14}$}

Ingreso separado del contacto infeccioso en una habitación individual, en incubadora, con medidas de aislamiento de contacto y por gotas, monitoreo de signos vitales (frecuencia cardiaca y respiratoria, temperatura, presión arterial y saturación de oxígeno) y vigilancia clínica. El inicio de la alimentación dependerá de la condición clínica. Se tomará RT-PCR para SARS-CoV-2, biometría hemática, PCR, pruebas de función renal, hepática, biomarcadores cardiacos, radiografía de tórax y abdomen. El tratamiento clínico no difiere del que se indica al neonato con los mismos síntomas: se aplican las medidas de soporte que hagan falta. En caso de dificultad respiratoria aguda grave, se va- lorará la administración de surfactante a dosis habituales, ventilación de alta frecuencia y óxido nítrico inhalado. Por ahora no existe evidencia suficiente para recomendar un tratamiento específico contra SARS-CoV2 para el recién nacido con COVID-19 confirmado. No obstante, esta información podría cambiar rápidamente debido a los resultados de varios ensayos clínicos en marcha. Evitar la indicación innecesaria de antibióticos y evitar los esteroides, por cualquier vía. Evitar la visita de familiares.

\section{Neonato asintomático y madre positiva}

Si los recursos para el aislamiento no están disponibles y las condiciones clínicas de la madre lo permiten, el recién nacido puede alojarse con ella. Deben permanecer aislados de otros casos sospechosos o confirmados y la madre puede lactar después de la adecuada higiene de manos, glándula mamaria y uso de cubrebocas N95. Mientras no se esté lactando deben permanecer separados, a una distancia de 2 metros y la madre permanecer con mascarilla N95. ${ }^{13,14}$

Criterios para el alta ${ }^{13,14}$

- Infección asintomática: 2 PCR para SAR CoV-2 de la vía aérea con intervalo de 48 horas negativas.

- Infección leve: temperatura normal por más de 3 días, con disminución evidente de los síntomas y dos pruebas PCR para SAR CoV-2 negativas de la vía aérea con intervalo de 48 horas.

- Infección severa: temperatura normal por más de 3 días, con disminución de los síntomas y radiológica pulmonar, 2 pruebas negativas PCR para SAR CoV-2 de la vía aérea, con intervalo de 48 horas. 
Antes del alta hospitalaria deben explicarse al cuidador todas las precauciones (asilamiento de personas o familiares de riesgo) y datos de alarma (irritabilidad, rechazo a la vía oral, datos de dificultad respiratoria, inestabilidad de la temperatura, etc.), seguimiento por vía telefónica o videollamada diaria en los siguientes 14 días posteriores al alta hospitalaria.

\section{Puntos a recordar}

- La evidencia actual no es concluyente en relación con la posibilidad de transmisión vertical.

- El neonato puede adquirir SARS-CoV-2 en cualquier momento después del nacimiento y generar una enfermedad grave.

- El cuadro clínico es inespecífico y, en parte, desconocido.

- Para todos los procedimientos que producen aerolización debe utilizarse equipo de protección personal completo.

- El primer hisopado para pruebas PCR para SAR CoV-2 debe practicarse entre las 24 y 36 horas, repetir 24 horas después.

- Practicar el hisopado de dos sitios simultáneamente (nasofaringe, orofaringe, aspirado endotraqueal o lavado bronquial) y rectal.

- En los neonatos con PCR para SAR CoV-2 positivas deben practicarse pruebas adicionales cada 48 horas hasta obtener dos pruebas negativas consecutivas.

- A la fecha no existe un medicamento útil y efectivo indicado en enfermos SAR CoV-2.
- Los hospitales con recursos limitados para las pruebas pueden tomar decisiones individuales de riesgo-beneficio con respecto a las pruebas.

\section{CONCLUSIONES}

Con más de 6 millones de casos de COVID-19 en todo el mundo, la proporción de neonatos con la enfermedad es aún baja. Además, el COVID-19 neonatal parece adquirirse después del nacimiento, aunque no está descartada la transmisión vertical. El cuadro clínico es inespecífico, el sistema respiratorio es el más vulnerable, por lo que es indispensable implementar un sistema de apoyo respiratorio con prácticas seguras que incluyen: aislamiento adecuado del paciente, equipo de protección personal óptimo y uso de filtros virales en los circuitos de los dispositivos de ventilación invasiva o no invasiva. Las recomendaciones aquí descritas son planteamientos fundamentados en la bibliografía y la opinión personal. Conforme haya mayor evidencia, estas recomendaciones cambiarán para que el personal de salud tome mejores decisiones para minimizar el daño, mejorar el futuro del neonato y mantener la protección y seguridad del equipo de salud. Hay que recordar que la información está cambiando rápidamente y los médicos debemos estar atentos a las actualizaciones conforme el estado de conocimiento evoluciona.

\section{REFERENCIAS}

1. Wang $L$, et al. Diagnosis and management plan of pneumonia with new coronavirus infection (trial version 4). Beijing: National Health and Health Commission, 2020.

2. World Health Organization. Laboratory testing for 2019 novel coronavirus (2019-nCoV) in suspected human cases. (2020-01-14). https://www.who.int/docs/default-source/ coronaviruse/20200114-interim-laboratory-guidance version. pdf?sfvrsn=6967c39b_4\&download=true

3. Wang $L$, et al. Chinese expert consensus on the perinatal and neonatal management for the prevention and control 
of the 2019 novel coronavirus infection (First edition). Ann Transl Med 2020; 8 (3): 47. doi: 10.21037/atm.2020.02.20

4. Xiaolu Ma, et al. Neonatal Management During the Coronavirus Disease (COVID-19) Outbreak: The Chinese Experience. NeoReviews. 2020; 21(5) e293 -297. doi. org/10.1542/neo.21-5-e293

5. Puopolo KM, et al. Initial Guidance: Management of Infants born to Mothers with COVID-19. 2020 Apr 2020 American Academy of Pediatrics Committee on Fetus and Newborn, Section on Neonatal Perinatal Medicine, and Committee on Infectious Diseases. https://downloads.aap.org/AAP/PDF/ COVID\%2019\%20Initial\%20Newborn\%20Guidance.pdf

6. Secretaría de Salud. Norma Oficial Mexicana NOM-025SSA3-2013, Para la organización y funcionamiento de las unidades de cuidados intensivos. Sep 2013.

7. Li AM, Ng PC. Severe acute respiratory syndrome (SARS) in neonates and children. Arch Dis Child Fetal Neonatal. Ed 2005; 90: F461-5.

8. Lu Q, Shi Y. Coronavirus disease (COVID-19) and neonate: What neonatologist need to know. J Med Virol. 2020;1-4. https://doi.org/10.1002/jmv.25740.
9. Chandrasekharan $\mathrm{P}$, et al. Neonatal resuscitation and postresuscitation care of infants born to mothers with suspected or confirmed SARS-CoV-2 Infection. Am J Perinatol 2020 e-pub. doi.org/10.1055/s-0040-1709688.

10. Shalish W, et al. COVID-19 and Neonatal Respiratory Care: Current Evidence and Practical Approach. Am J Perinatol 2020 e-pub. doi: 10.1055 / s-0040-1710522.

11. Marraro G, Spada C. Consideration of the respiratory support strategy of severe acute respiratory failure caused by SARS-CoV-2 infection in children. Chin J Contemp Pediatr. 2020; 22 (3): 183-94.

12. Ma X, Zhu J, Du L. Neonatal Management During the Coronavirus Disease (COVID-19) outbreak: The Chinese experience. NeoReviews. 2020 M; 2 (5). https://doi. org/10.1542/neo.21-5-e293

13. Estrada-Ruelas I, et al. Recomendaciones para el manejo del recién nacido en relación con la infección por SARSCoV-2. Med Int Méx. 2020; 36 (S2): S74-S81.

14. Kallem VR, Sharma D. COVID 19 in neonates. J Matern Fetal Neonatal Med 2020; 1-9. doi: 10.1080/14767058.2020.1759542 